\title{
Dengue Fever in Pregnancy Mimicking Obstetric Hemorrhage
}

\author{
${ }^{1}$ Meghana Narendrabhai Mehta, ${ }^{2} \mathrm{~J}$ itesh Mafattal Shah, ${ }^{2}$ Ashvin Dayalal Vachhani \\ ${ }^{2}$ Archish Ishvarbhai Desai \\ ${ }^{1}$ Assistant Professor, Department of Obstetrics and Gynecology, Surat Municipal Institute of Medical Education \\ and Research, Surat, Gujarat, India \\ ${ }^{2}$ Associate Professor, Department of Obstetrics and Gynecology, Surat Municipal Institute of Medical Education \\ and Research, Surat, Gujarat, India
}

Correspondence: J itesh Mafatlal Shah, Associate P rofessor, Department of Obstetrics and Gynecology, D-503, Citizen Heights
Punagam R oad, Magob, S urat-395010, Gujarat, India, Phone: 09426228108, Fax: 0261-2343241, e-mail: drjiteshshah@ gmail.com

\section{ABSTRACT}

Dengue is a major public health problem in the tropical and subtropical area. Dengue fever is caused by one of the four dengue virus serotypes of the genus Flavivirus, family flaviviridae, RNA virus. ${ }^{1-3}$ Dengue is transmitted to humans by the mosquito Aedes aegypti. The principal maternal complications are abortion, premature labor, retroplacental hematoma leading to antepartum hemorrhage and hemorrhage during and after delivery. Fetal complications are prematurity, intrauterine fetal death (IUFD), acute fetal distress in labor, maternal-fetal (vertical) transmission and neonatal death. Management of dengue fever is conservative with intravenous fluid replacement and close observation of vital signs and bleeding.

Keywords: Dengue fever, Obstetric hemorrhage.

\section{INTRODUCTION}

Dengue, a major public health problem in the tropical and subtropical area with around 100 million cases each year, is responsible for 25,000 deaths worldwide. ${ }^{1}$ Dengue fever in pregnancy can lead to many maternal and fetal complications.

\section{CASE REPORT}

M rs XYZ, aged 35 years, G 7P6A 0 admitted in labor room at $2.30 \mathrm{am}$ on $11 / 7 / 2010$ with 6 months amenorrhea with vaginal bleeding since 2 hours. She had previous six full-term vaginal deliveries; five female children alive and one female child expired.

On examination, temperature raised to $99^{\circ} \mathrm{F}$, pallor-present, pulse-110/min, BP-130/80 mm Hg, splenomegaly-present, respiratory and cardiovascular systems were normal. On abdominal examination, uterus was 26 weeks in size, tonically contracted and fetal heart sounds absent. Per speculum examination- bleeding present. UI trasound showed intrauterine demise of twin fetuses of 24 weeks with large retroplacental clot and no previa. Cervix was closed, tubular and not effaced. In investigations: $\mathrm{Hb} 7.1 \mathrm{gm} / \mathrm{dl}$, platel et count 73,000/dl, PT and aPTT normal. Emergency preterm LSCS was done for abruptio placentae with unfavorable cervix. T wo femal e fetuses of $600 \mathrm{gm}$ delivered stillborn. A round $700 \mathrm{gm}$ of retroplacental clots present. Hemostasis secured and abdomen closed in layers.

On the postoperative day, she progressively developed pallor, tachycardia, hypotension, reduction in urine output, abdominal dissension and fever. A fter 12 hours, relaparotomy was done for hemoperitoneum due to suspected primary hemorrhage. A bdomen was opened through the same incision. A round $600 \mathrm{ml}$ of blood was present in abdomen, multiple oozing was present from all layers of abdomen and no active bleeding vessel was found. D rains were kept in peritoneal cavity and abdominal wall, and closure were done. A round $800 \mathrm{ml}$ blood drained through drainage tube in next 12 hours. Her platelet count was dropped up to $29,000 / \mathrm{dl}$ and due to continuous fever, blood sent for dengue serology. D engue I gM came positive. Hemoperitoneum subsided after 24 hours and then she developed pleural effusion and ascites. W ith intensive monitoring, she started improvement after 72 hours. Stitches were removed on 9th day and discharged in good condition. Eight units of packed cell volume (PCV), eight units of fresh frozen plasma (FFP), and four units of platelets (PRP) were infused. She was normal on follow-up on day 15.

\section{DISCUSSION}

Dengue fever is caused by one of the four dengue virus serotypes of the genus Flavivirus, family flaviviridae, RNA virus. ${ }^{1-3}$ Dengue is transmitted to humans by the mosquito Aedesaegypti. Currently, the incidence of dengue has been increasing among adults. ${ }^{3}$ Its symptoms range from pseudoinfluenza with headache, fever, muscle and joint pains to dengue hemorrhagic fever (DHF). ${ }^{1}$ The WHO criteria for diagnosis of DHF fever include: (a) fever (b) hemorrhagic tendency with thrombocytopenia, (c) evidence of plasma leak as evidenced by hematocrit 20\% higher than expected, and (d) pleural effusion and ascites. ${ }^{5} \mathrm{~A} / \mathrm{l}$ above al ong with a weak, rapid pulse, narrow pulse pressure or hypotension, cold clammy skin and restlessness constitutes the dengue shock syndrome. The physiologic changes that occur during pregnancy, such as hemodilution or ability to coagulate, may mask thrombocytopenia, leukopenia or hematocrit increase. ${ }^{1}$ Hepatic and 
hematological problems can also be observed with other obstetric complications, such as morning sickness and HEL L P syndrome, ${ }^{1}$ which may result in an underestimate of dengue. The serology and molecular studies are available to confirm the diagnosis of dengue. However, IgM capture ELISA is a widely used, simpleand rapid method to detect dengue specific IgM antibodies. ${ }^{2}$

The principal maternal complications are abortion, premature labor, retroplacental hematoma leading to antepartum hemorrhage, and hemorrhage during and after delivery. Fetal complications are prematurity, intrauterine fetal death (IUFD), acutefetal distress in labor, maternal-fetal (vertical) transmission and neonatal death. ${ }^{1-7}$ B leeding during pregnancy and delivery occurs due to thrombocytopenia. So, it is recommended that platel ets be maintained at least around 50,000/dl at near-term and delivery. $V$ ertical transmission of dengue has been reported in several studies leading to hemorrhagic tendency in neonates. M ost neonates develop fever within 4 to 5 days of life and may require platel et transfusion.

$M$ anagement of dengue fever is conservative with intravenous fluid replacement and close observation of vital signs and bleeding. ${ }^{3,7}$ Platelet transfusion is indicated when there is significant bleeding. As there are no specific therapeutic measures, mosquito avoidance measures are necessary to prevent dengue fever. ${ }^{4}$

\section{CONCLUSION}

M ore cases of dengue fever in pregnancy can be found because of rising incidence. It can lead to many maternal and fetal complications including hemorrhage due to thrombocy topenia and vertical transmission.

\section{REFERENCES}

1. Basurko C, Carles G, Y oussef M, Guindi WEF. M aternal and fetal consequences of dengue fever during pregnancy. Eur J Obstet Gynecol Reprod Biol Nov 2009;147(1):29-32.

2. Singh N, Sharma KA, Dadhwal V, Mittal S, Selvi AS. A successful management of dengue fever in pregnancy: Report of two cases. Indian J M ed M icrobiol 2008;26:377-80.

3. Phupong V. BM C pregnancy and childbirth 2001;1:7.

4. Carroll ID, Toovey S, V an GA. Dengue fever and pregnancy: A review and comment. Travel Med Infect Dis M ay 2007; 5(3):183-88.

5. Carles $G$, Peiffer $H$, Talarmin A. Effects of dengue fever during pregnancy in French Guiana. Clin Infectious Dis 1999;28: 637-40.

6. Carles G, Talarmin A, Peneau C, B ertsch M . D engue fever and pregnancy: A study of 38 cases in French Guiana. J Gynecol Obstet Biol Reprod (Paris) Dec 2000;29(8):758-62.

7. Wiwanitkit $V$. Dengue hemorrhagic fever in pregnancy: A ppraisal on Thai cases. J V ect B orne Dis 43;203-05. 